\title{
Molecular Docking and Quantum Mechanical Studies on Pelargonidin-3-Glucoside as Renoprotective ACE Inhibitor
}

\author{
Talambedu Usha, ${ }^{1}$ Pranav Tripathi, ${ }^{2}$ Veena Pande, ${ }^{3}$ and Sushil Kumar Middha ${ }^{3}$ \\ ${ }^{1}$ DBT-BIF Centre, Department of Biotechnology, Maharani Lakshmi Ammanni College for Women, Malleswarm, \\ Bangalore, Karnataka 560012, India \\ ${ }^{2}$ Department of Biotechnology, G.B. Pant Engineering College, Uttarakhand 246194, India \\ ${ }^{3}$ DBT-BIF Centre, Department of Biotechnology, Kumaun University, Bhimtal Campus, Nainital, Uttrakhand 263136, India
}

Correspondence should be addressed to Sushil Kumar Middha; sushil.middha@gmail.com

Received 21 January 2013; Accepted 24 February 2013

Academic Editors: B. Oliva and A. Qiao

Copyright (C) 2013 Talambedu Usha et al. This is an open access article distributed under the Creative Commons Attribution License, which permits unrestricted use, distribution, and reproduction in any medium, provided the original work is properly cited.

\begin{abstract}
Background and Aim. Despite tangible progress in recent years, substantial therapeutic challenges remain unexplored in nephropathy, particularly in diabetic patient. Addressing these challenges requires identification of novel drugs and development of noninvasive and cost-effective methods to select the most appropriate therapeutic option for the disease. Angiopathic nephropathy is one of the complications of diabetes mellitus and is becoming the single most important reason for end-stage renal disease in the western world. This study has investigated the inhibitory effect of a library naturally occurring nonprotein compounds that inhibit angiotensin converting enzyme (ACE). Materials and Methods. Docking studies of ACE protein with natural compounds and synthetic commercial drug perindopril were done using AutoDock, FlexX, and Hex. Toxicity predictions were carried out using OpenTox. Quantum mechanical properties were studied using GAMESS. Results. Pelargonidin-3-glucoside could be used as a potent renoprotective drug candidate, which inhibits ACEII. It has low toxicity and its quantum mechanical properties are comparable to those of commercial drugs.
\end{abstract}

\section{Introduction}

Angiotensin converting enzyme (ACE) is an active participant in the body's renin-angiotensin-aldosterone system for mediation of extracellular volume and arterial vasoconstriction. Secretion of this enzyme is carried by pulmonary and renal endothelial cells to catalyze the conversion of decapeptide angiotensin I to octapeptide angiotensin [1]. Apart from the normal catalysis activity, ACE also degrades bradykinin thus acting as a vasoconstrictor [2]. These two actions make ACE inhibition a potent target in the treatment of conditions such as hypertension, heart failure, and diabetic nephropathy. Inhibition of ACE results in the dwindled formation of angiotensin II and reduced catabolism of bradykinin, leading to systematic dilation of the arteries and veins and a decrease in arterial blood pressure. Inhibition of this enzyme also decreases the risk of end-stage renal disease (ESRD) in diabetics [3]. perindopril is a synthetic chemical drug which inhibits ACE; however, it causes dysfunctioning of the left ventricle of in Duchenne muscular dystrophy [4]. Considering the side effects of perindopril, the present study investigates the inhibitory effect of natural compounds in comparison with perindopril by insilico approach.

\section{Materials and Methods}

To investigate the protein ligand interaction, the natural compounds and perindopril were docked into the active site of ACE predicted by pocket finder. The crystal structure of ACE was retrieved from the RCSB Protein Data Bank (PDB entry code 2XY9). Structures of all the compounds were constructed and minimized using MarvinSketch [5]. Docking and hydrogen bonding were done using AutoDock Vina [6], Flex-X [7], HEX6.3 [8, 9], and SPDBV [10], respectively, at default parameters. The molecular dynamics was explored using MD Movie part of UCSF Chimera [11]. The ADME 
TABLE 1: Molecular and ADME properties of compounds.

\begin{tabular}{|c|c|c|c|c|c|c|c|c|c|c|}
\hline & $\begin{array}{l}\text { Molecular } \\
\text { weight } \\
\text { (in gms) }\end{array}$ & $\begin{array}{l}\text { H-bond } \\
\text { acceptor }\end{array}$ & $\begin{array}{l}\text { H-bond } \\
\text { donor }\end{array}$ & $\log P$ & $\begin{array}{l}\text { Solubility } \\
(\mathrm{mg} / \mathrm{mL})\end{array}$ & $\begin{array}{l}\text { Molar } \\
\text { refractivity }\end{array}$ & $\begin{array}{l}\text { TPSA } \\
\left(\AA^{2}\right)\end{array}$ & $\begin{array}{l}\text { AutoDock } \\
\text { scores }\end{array}$ & $\begin{array}{l}\text { FlexX } \\
\text { scores }\end{array}$ & $\begin{array}{c}\text { Hex } \\
\text { scores }\end{array}$ \\
\hline $\begin{array}{l}\text { Pelargonidin- } \\
\text { 3-glucoside }\end{array}$ & 433.385 & 9 & 7 & 0.676 & 0.521 & 106.2712 & 173.21 & 8.7 & -27.7 & -359.5 \\
\hline $\begin{array}{l}\text { Perindopril } \\
\text { (commercial } \\
\text { drug) }\end{array}$ & 368.467 & 6 & 2 & 0.9 & 0.02928 & 96.176 & 95.9 & 5.2 & -27.3 & -239.2 \\
\hline
\end{tabular}

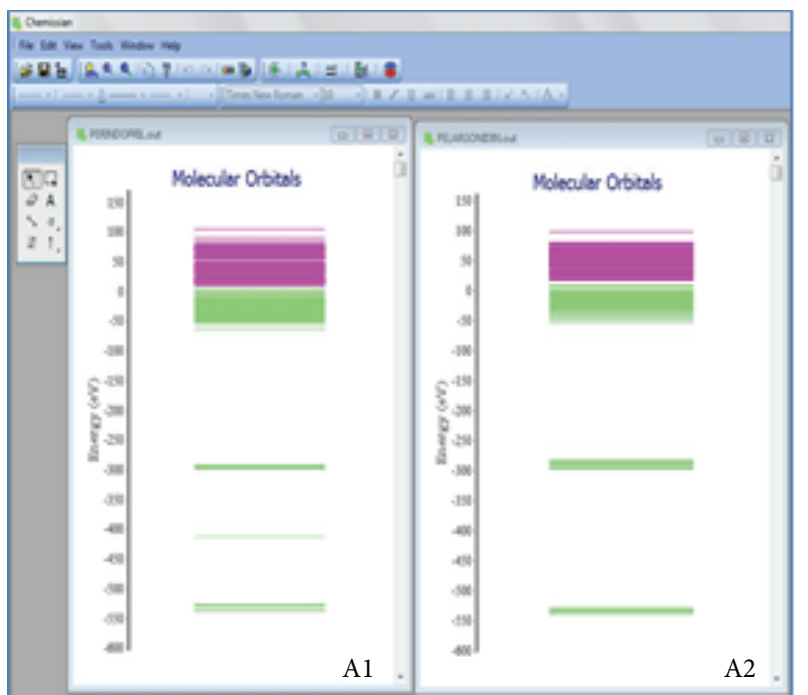

Figure 1: (A1\&A2) Energy band diagrams of molecular orbitals obtained using GAMESS software and viewed in Chemissian.

values of natural compounds were calculated online using ADME tool of SIMCYP [12]. Toxicity of the lead compound was calculated using OpenTox online tool [13]. To increase the firmness of the observations, the natural compounds and commercial drugs were quantum mechanically examined and positive results are therefore investigated and analyzed using GAMESS [14] and CHEMISSIAN [15].

\section{Results}

The acute toxicity in fish was estimated to be about 0.53 (F96h-LogLC50 mmol/L) calculated using OpenTox server. The docking results with molecular, ADME properties of the best natural compound, and the perindopril are listed in Table 1 . The above scores establish pelargonidin-3-glucoside as a better compound in comparison to commercial drugs like perindopril.

The quantum mechanical properties of the lead compound were examined along with the commercial drug to investigate the energy band diagrams of the molecular orbitals and the electron densities based on density functional Theory. The energy bands reveal a positive correlation between drug and lead compound as the molecular orbitals are depicted in the same energy band (Figure 1).
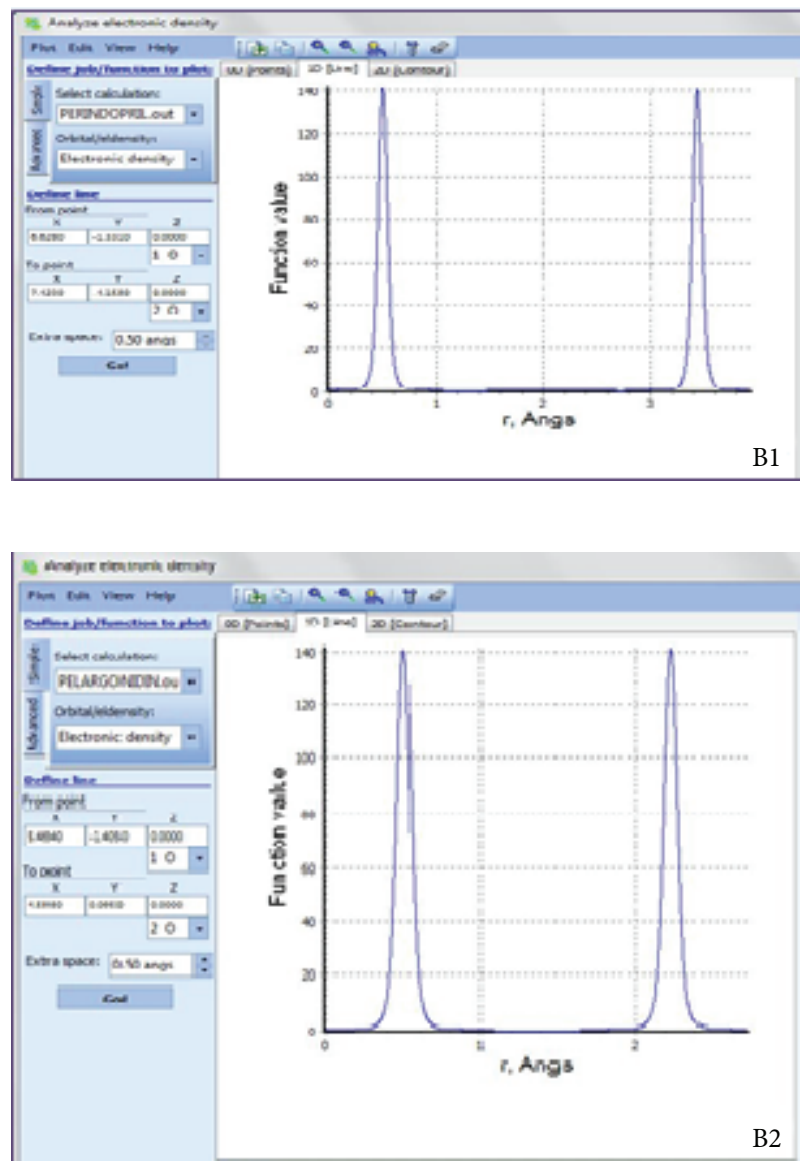

Figure 2: (B1\&B2) Comparison of electron densities of natural compound under investigation with available drug using DFT in GAMESS.

The electron densities also depict affirmative results to establish similarity between the lead compound and commercial drug as shown in Figure 2.

Assenting prediction of the binding site for the inhibition of the enzyme has also been achieved as depicted in Figure 3.

\section{Discussions}

Pelargonidin-3-glucoside is a zenith anthocyanin present in of Zea mays [16]. The above mentioned results for renoprotection are the very first of its type in the current scientific arena. On the basis of results of docking score, molecular dynamics, hydrogen bonding pattern, and ADME-T values, we can 


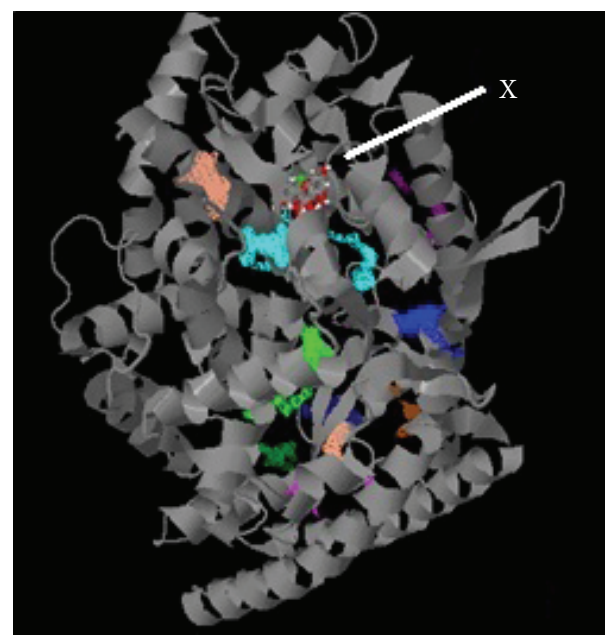

FIGURE 3: $\mathrm{X}$ shows binding affinity prediction and binding site analysis, where ligand is shown in red and white color.

conclude that natural compound pelargonidin-3-glucoside from Zea mays is found to be unsurpassed in comparison with synthetic drugs like perindopril. The ADME properties showed satisfactory results for the $\log P, \log (\mathrm{Sw})$, solubility, molar refractivity, and topological PSA of pelargonidin3-glucoside. The toxicity minutiae were calculated using OpenTox server. The compound was evaluated to have $\mathrm{pKa}$ SMARTS of 4.79 , and regarding biodegradability, class II like persistence was reckoned. Pelargonidin-3-glucoside is also analyzed as a non-carcinogen and non-irritant for eye and skin. Pelargonidin 3-O- $\beta$-glucopyranoside is a natural colorant found in strawberries [17], pomegranate fruit [18], peel $[19,20]$, and flowers [21]. The quantum mechanical properties are inferring a compelling possibility of showing drug-like typescript by analysis of electron densities and energy band diagram of molecular orbitals which are similar to perindopril. Thus this compound can be deliberated as a better compound against hypertension and for decreasing the risk of ESRD.

\section{Acknowledgments}

The authors are thankful to DBT-BIF Center, Maharani Lakshmi Ammanni College for Women and Kumaun University for providing the laboratory and licensed facility.

\section{References}

[1] M. Moser, C. Rosendorff, and W. B. White, "Angiotensinconverting enzyme inhibitors and angiotensin II receptor blockers: is there a difference in response and any advantage to using them together in the treatment of hypertension?" Journal of Clinical Hypertension, vol. 10, no. 6, pp. 489-496, 2008.

[2] M. E. Marketou and P. E. Vardas, "Bradykinin in the treatment of arterial hypertension: friend or foe?" Hellenic Journal of Cardiology, vol. 53, pp. 91-94, 2012.

[3] S. Suissa, T. Hutchinson, J. M. Brophy, and A. Kezouh, "ACEinhibitor use and the long-term risk of renal failure in diabetes,"
Kidney International, vol. 69, no. 5, pp. 913-919, 2006.

[4] D. Duboc, C. Meune, G. Lerebours, J. Y. Devaux, G. Vaksmann, and H. M. Bécane, "Effect of perindopril on the onset and progression of left ventricular dysfunction in Duchenne muscular dystrophy," Journal of the American College of Cardiology, vol. 45 , no. 6, pp. 855-857, 2005.

[5] "Marvin was used for drawing, displaying and characterizing chemical structures, substructures and reactions, Marvin 5.8.0 (324)," 2008, ChemAxon, http://www.chemaxon.com/.

[6] O. Trott and A. J. Olson, "Software news and update AutoDock Vina: improving the speed and accuracy of docking with a new scoring function, efficient optimization, and multithreading," Journal of Computational Chemistry, vol. 31, no. 2, pp. 455-461, 2010.

[7] M. Rarey, B. Kramer, T. Lengauer, and G. Klebe, "A fast flexible docking method using an incremental construction algorithm," Journal of Molecular Biology, vol. 261, no. 3, pp. 470-489, 1996.

[8] D. W. Ritchie and V. Venkatraman, "Ultra-fast FFT protein docking on graphics processors," Bioinformatics, vol. 26, no. 19, Article ID btq444, pp. 2398-2405, 2010.

[9] B. Bhattacharjee, T. Usha, S. Sadegh et al., "Computer aided screening of inhibitors to $5-\alpha$ reductase type 2 for prostate," Bioinformation, vol. 6, no. 7, pp. 262-265, 2011.

[10] B. Bhattacharjee, R. M. Jayadeepa, R. Anantharamanan, S. S. Pillay, N. Kumari, and S. K. Middha, "Screening of novel inhibitors for MEK1 induced Breast Cancer-An Insilico Approach," EMBnet Journal A, vol. 16, pp. 25-26, 2009.

[11] E. F. Pettersen, T. D. Goddard, C. C. Huang et al., "UCSF Chimera-a visualization system for exploratory research and analysis," Journal of Computational Chemistry, vol. 25, no. 13, pp. 1605-1612, 2004.

[12] D. B. Turner, A. Rostami-Hodjegan, G. T. Tucker, and K. R. Yeo, "Prediction of non-specific hepatic microsomal binding from radily available physicochemical properties," Drug Metabolism Reviews, vol. 38, no. 1, p. 162, 2006.

[13] E. L. Willighagen, N. Jeliazkova, B. Hardy, R. C. Grafström, and O. Spjuth, "Computational toxicology using the OpenTox application programming interface and Bioclipse," BMC Research Notes, vol. 4, p. 487, 2011.

[14] M. W. Schmidt, K. K. Baldridge, J. A. Boatz et al., "General atomic and molecular electronic structure system," Journal of Computational Chemistry, vol. 14, no. 11, pp. 1347-1363, 1993.

[15] http://www.chemissian.com/.

[16] Y. S. Moreno, G. S. Sánchez, D. R. Hernández et al., "Characterization of anthocyanin extracts from maize kernels," Journal of Chromatography Science, vol. 43, no. 9, pp. 483-487, 2005.

[17] C. Felgines, O. Texier, C. Besson, B. Lyan, J. L. Lamaison, and A. Scalbert, "Strawberry pelargonidin glycosides are excreted in urine as intact glycosides and glucuronidated pelargonidin derivatives in rats," British Journal of Nutrition, vol. 98, no. 6, pp. 1126-1131, 2007.

[18] Y. Noda, T. Kaneyuki, A. Mori, and L. Packer, "Antioxidant activities of pomegranate fruit extract and its anthocyanidins: delphinidin, cyanidin, and pelargonidin," Journal of Agricultural and Food Chemistry, vol. 50, no. 1, pp. 166-171, 2002.

[19] S. K. Middha and T. Usha, "An in vitro new vista to identify hypoglycemic activity," International Journal of Fundamental and Applied Science, vol. 1, no. 2, pp. 27-29, 2012.

[20] T. Tanaka, G. I. Nonaka, and I. Nishioka, "Tannins and related compounds. C. Reaction of dehydrohexahydroxydiphenic acid 
esters with bases, and its application to the structure determination of pomegranate tannins, granatins A and B," Chemical and Pharmaceutical Bulletin, vol. 38, no. 9, pp. 2424-2428, 1990.

[21] L. Zhang, Q. Fu, and Y. Zhang, "Composition of anthocyanins in pomegranate flowers and their antioxidant activity," Food Chemistry, vol. 127, no. 4, pp. 1444-1449, 2011. 

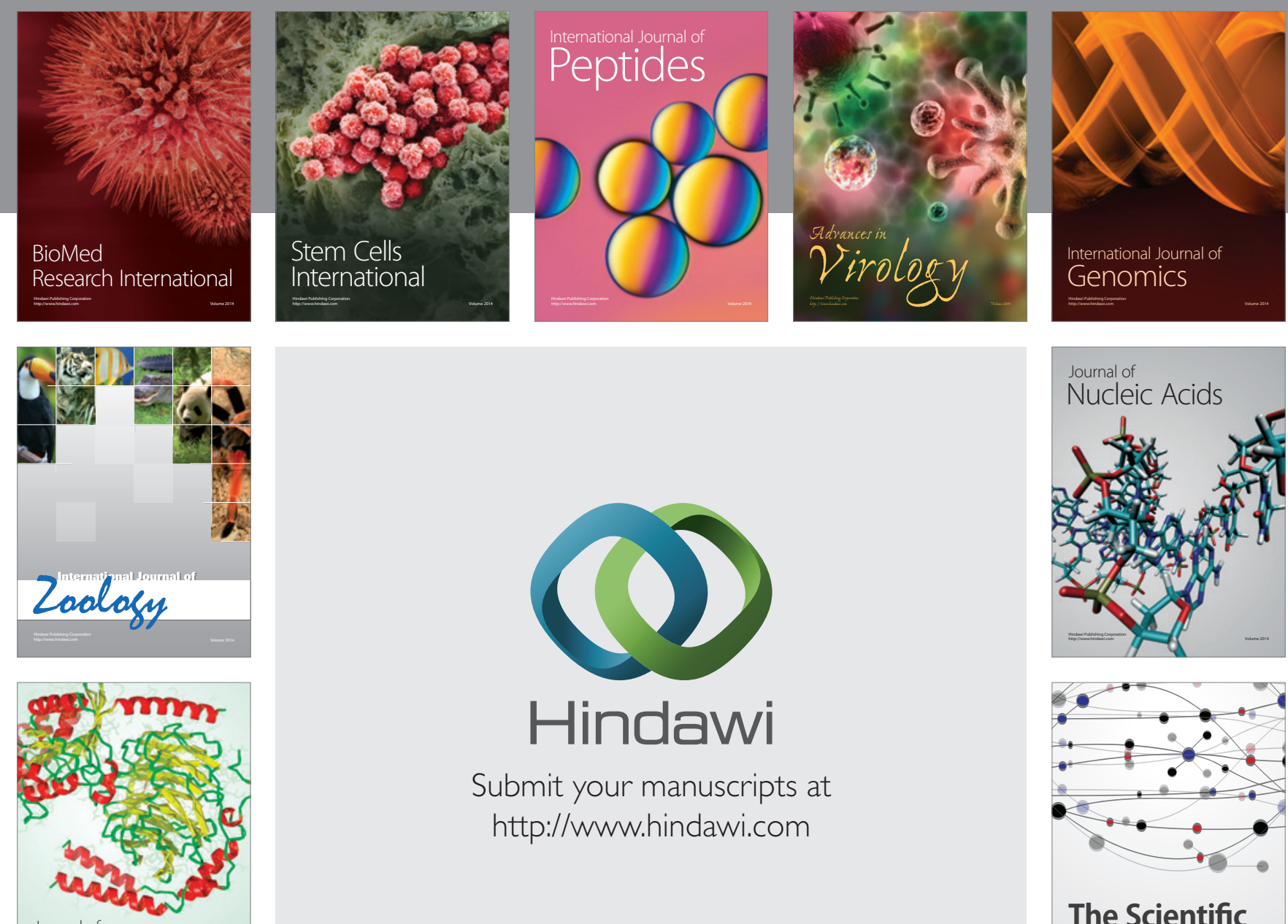

Submit your manuscripts at

http://www.hindawi.com

Journal of
Signal Transduction
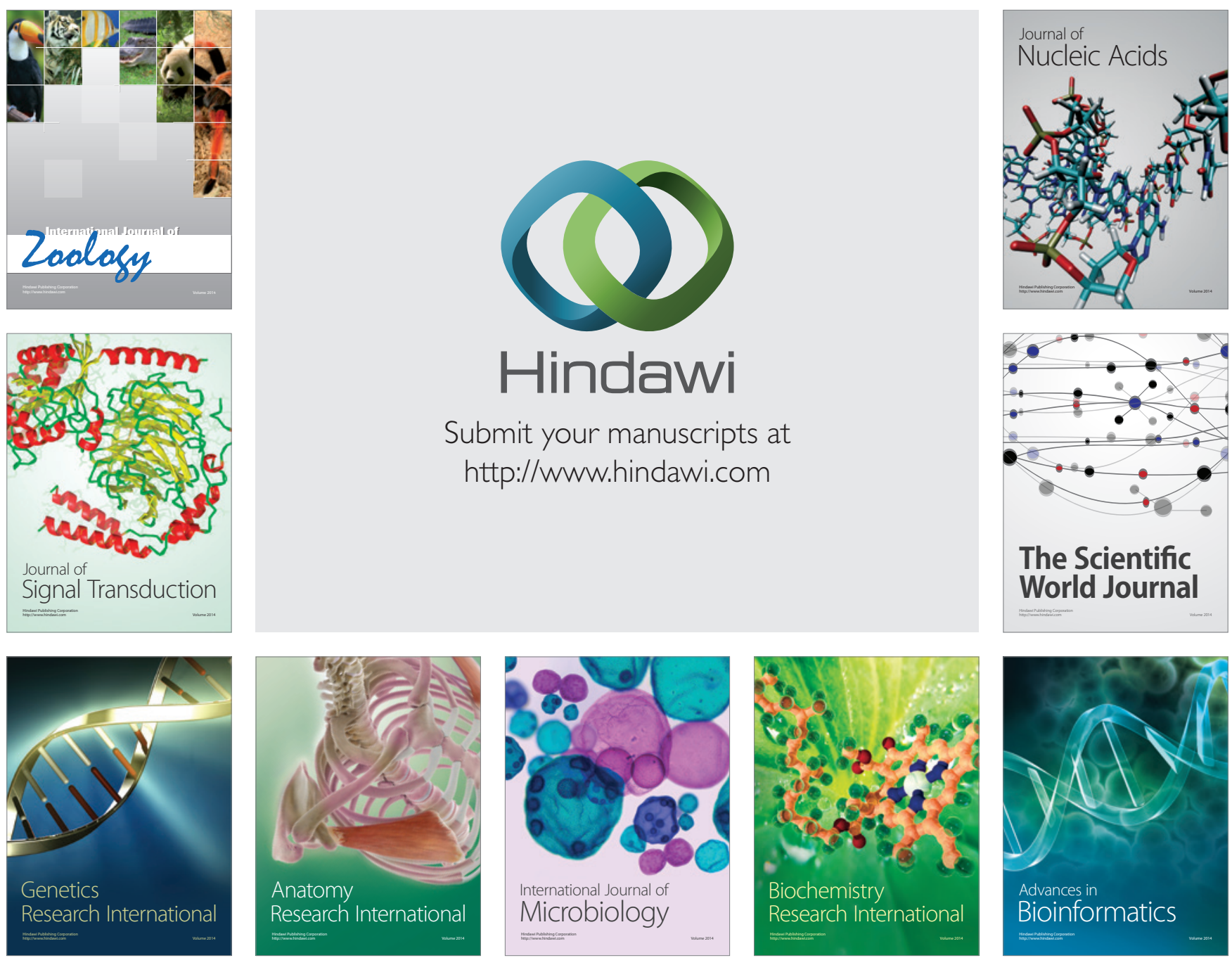

The Scientific World Journal
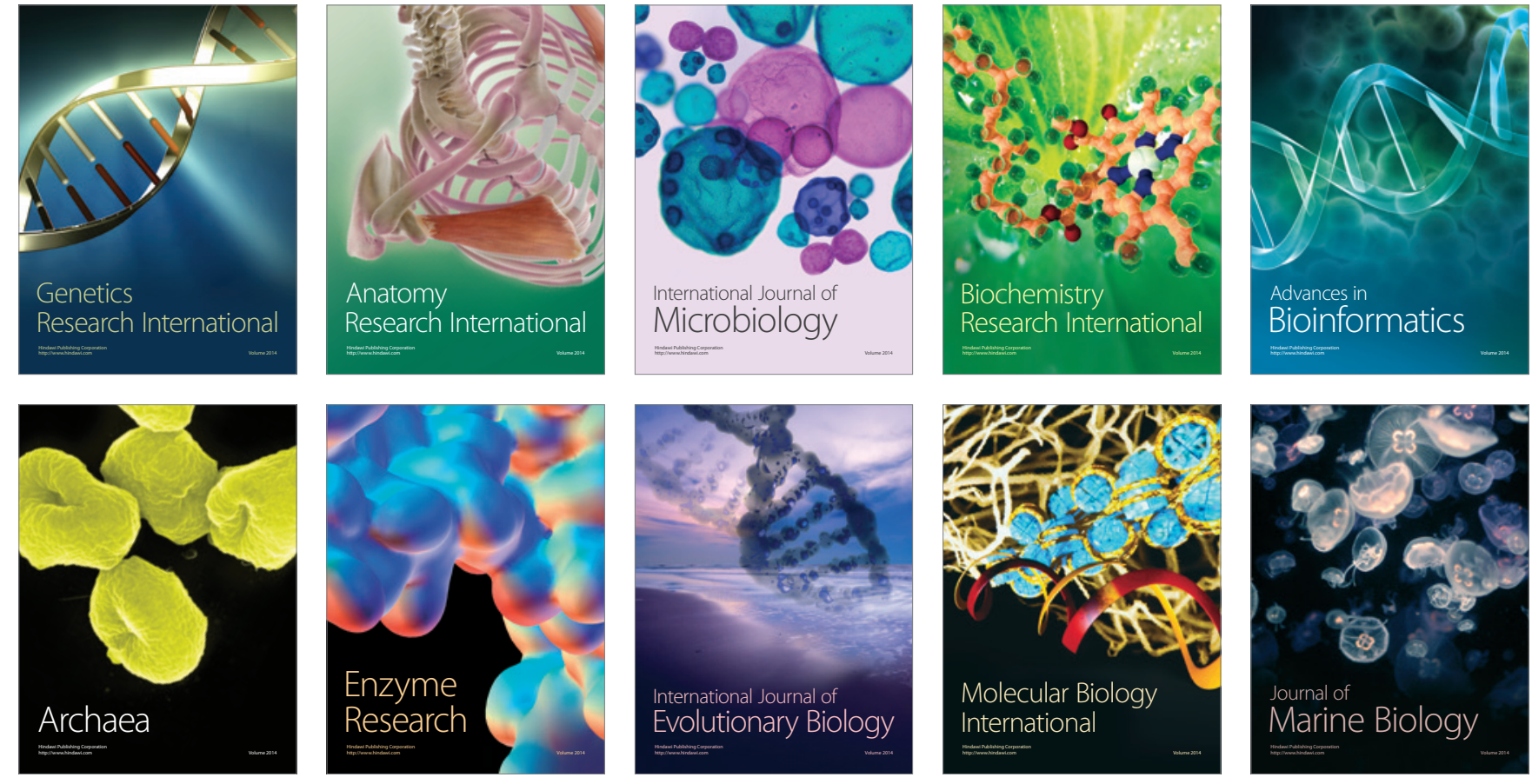